

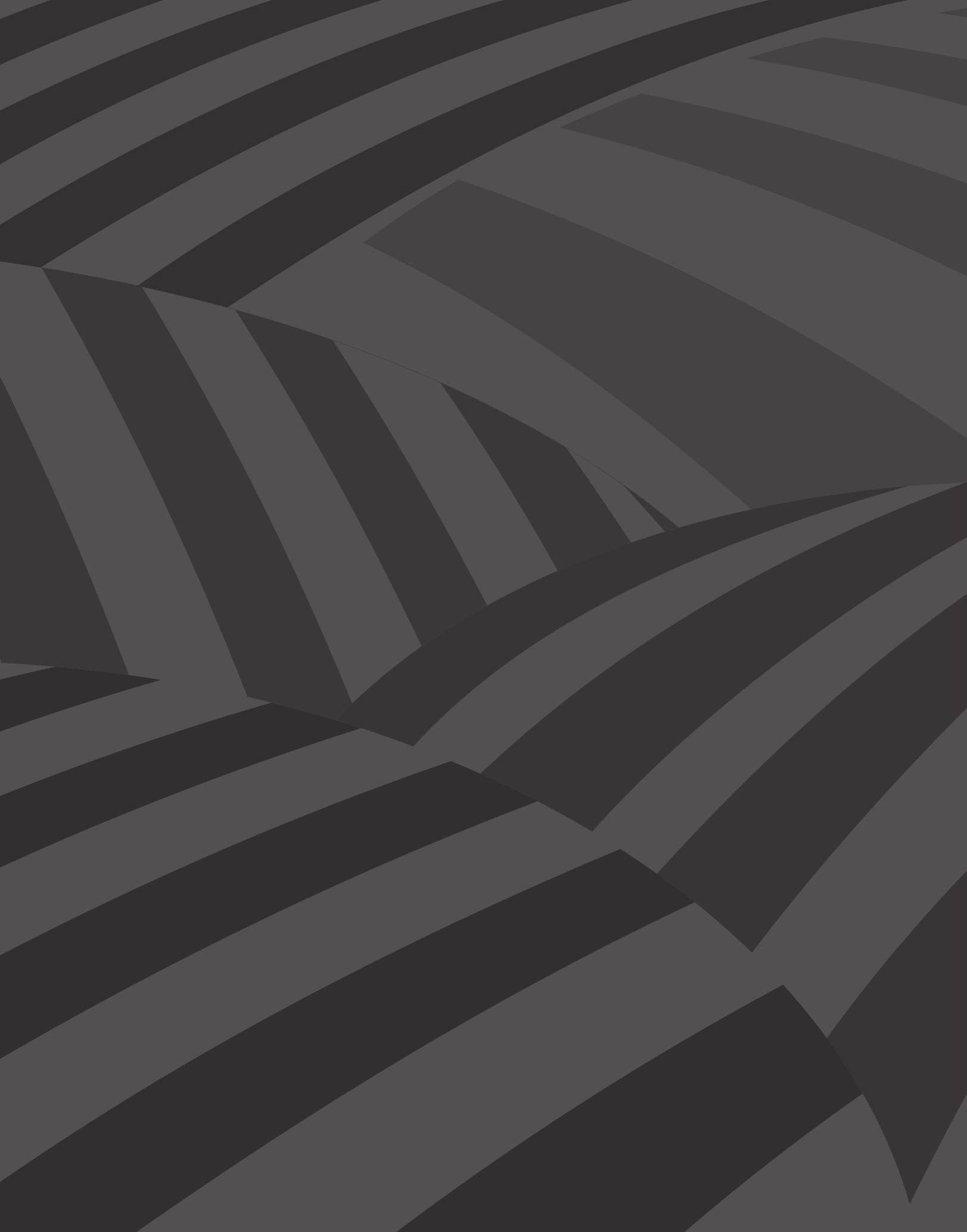




\section{Retos del diálogo social intercultural: el caso del PDET Alto Patía y Norte del Cauca}

Por: Edilberto Vergara Argüello* y Katerine Duque Duque**

Resumen: El presente artículo evidencia los retos del diálogo social intercultural en el proceso de implementación del Programa de Desarrollo con Enfoque Territorial (PDET), en la región Alto Patía y Norte del Cauca. Como primer elemento, se realiza un acercamiento conceptual sobre el diálogo social y la interculturalidad, teniendo en cuenta la experiencia del Instituto de Estudios Interculturales de la Pontificia Universidad Javeriana Cali. Seguido a lo anterior, se presenta un breve contexto de la región Alto Patía y Norte del Cauca, y se finaliza con la enumeración de retos políticos, institucionales, participativos y comunitarios del diálogo social intercultural en clave de implementación del PDET.

Palabras clave: diálogo social, paz, interculturalidad, desarrollo rural.

\section{Challenges of the Intercultural Social Dialogue: The case of PDET Alto Patía and Norte of Cauca}

Abstract: This article demonstrates the challenges of intercultural social dialogue in the process of implementing the Territorial Approach Development Program -PDET- in the Alto Patía and Norte of Cauca region. As the first element, a conceptual approach to social dialogue and interculturality is carried out, taking into account the experience of the Institute of Intercultural Studies of the Pontificia Universidad Javeriana Cali. Following the above, a brief context of the Alto Patía and Norte of Cauca region is presented, and concludes, with the enumeration of political, institutional, participatory and community challenges of intercultural social dialogue in terms of implementation of the PDET.

* Antropólogo de la Universidad Nacional de Colombia. Investigador de la línea de Movimientos Sociales y Construcción de Paz del Instituto de Estudios Interculturales de la Pontificia Universidad Javeriana de Cali. edilberto.vergara@javerianacali. edu.co.

** Coordinadora de la línea de investigación de Movimientos Sociales y Construcción de Paz. Antropóloga de la Universidad Nacional de Colombia y estudiante de la Maestría en Desarrollo, Interculturalidad y Paz Territorial de la Pontificia Universidad Javeriana de Cali. katerine.duque@javerianacali.edu.co. 
Keywords: Social dialogue, peace, interculturality, rural development

Cómo citar este artículo: Vergara Argüello, Edilberto y Duque Duque, Katerine (2020). Retos del diálogo social intercultural: el caso del PDET Alto Patía y Norte del Cauca. Revista Controversia, 214, 51-89.

Fecha de recepción: 29 de septiembre de 2019

Fecha de aprobación: 14 de febrero de 2020

\section{Introducción}

1 Estado colombiano ha vivido por más de cincuenta años la con-
frontación armada más larga de Suramérica, con el grupo guerri-
llero Fuerzas Armadas Revolucionarias de Colombia-Ejército del Pueblo (FARC-EP). Durante este periodo han surgido diversos esfuerzos para superar el conflicto, de los cuales se destacan las negociaciones y diálogo de 1982 con los acuerdos de La Uribe, en 1991-1992 los diálogos de paz de Caracas y Tlaxcala, y en 1998-2002 el proceso de paz de El Cagúan (Gutiérrez, 2012), acercamientos que no fueron exitosos.

Durante la última década, se avanzó en el diálogo exploratorio iniciado en el año 2012, que abrió las puertas para la firma del Acuerdo final para la terminación del conflicto y la construcción de una paz estable $y$ duradera, luego de más de cuatro años de deliberaciones entre la las FARC-EP y el Gobierno colombiano, en cabeza de Juan Manuel Santos. Este hecho histórico trajo consigo cambios económicos, sociales, políticos, territoriales, institucionales y normativos para el país.

Como objetivos centrales, el Acuerdo de Paz buscó:

i. Poner fin a la confrontación armada del conflicto y a las afectaciones a la sociedad colombiana. 
ii. Crear un nuevo capítulo en la historia colombiana, que permita integración territorial con mayor inclusión social, fortalecimiento de la democracia y creación de garantías para la participación en política. Todo con el propósito de la construcción de una paz estable y duradera (Gobierno Nacional y Farc-Ep, 2016).

Dentro del Acuerdo de Paz, se reconocieron enfoques transversales como el de género y étnico, y se resaltó el enfoque territorial que, como quedó consignado,

supone reconocer y tener en cuenta las necesidades, características y particularidades económicas, culturales y sociales de los territorios y las comunidades, garantizando la sostenibilidad socio-ambiental; y procurar implementar las diferentes medidas de manera integral y coordinada, con la participación activa de la ciudadanía. (Gobierno Nacional y Farc-Ep, 2016, p. 6).

El Acuerdo de Paz se estructuró en seis puntos: 1. Reforma rural integral, 2. Participación política, 3. Fin del conflicto, 4. Solución a drogas ilícitas, 5. Víctimas y 6. Implementación. Teniendo en cuenta lo anterior, el presente documento evidencia los retos del diálogo social intercultural en el marco del proceso de implementación del Programa de Desarrollo con enfoque Territorial (PDET), en la subregión Alto Patía y Norte del Cauca, correspondiente al punto 1. En ese sentido, se presenta un contexto sobre el estado de implementación del Acuerdo de paz firmado, a continuación se realiza un acercamiento conceptual al diálogo social y se evidencia la experiencia del Instituto de Estudios Interculturales de la Pontificia Universidad Javeriana de Cali. Más adelante se elabora un contexto del PDET de la subregión Alto Patía y Norte del Cauca y finaliza con el análisis de algunos retos del diálogo social intercultural para la construcción de paz en la subregión del PDET.

El concepto de paz territorial tomó fuerza en el contexto de estos diálogos de negociación y construcción de paz. En este documento, su concepción se cimentó bajo el precepto del cumplimiento de la Constitución Política de 
Colombia, artículo 22, en el que expone la paz como un derecho y deber de obligatorio cumplimiento, y el artículo 95, núm. 6, relativo al logro y mantenimiento de la paz (Gobierno Nacional y Farc-Ep, 2016).

De acuerdo con posturas gubernamentales de este periodo (2012-2016), la paz debe permitir la comprensión de los derechos de los ciudadanos y al mismo tiempo hacerlos valer, a partir del fortalecimiento de las instituciones, representadas en las normas que regulan lo público y que generan condiciones de convivencia y de cooperación, por lo cual se pone en el centro el diseño e implementación de políticas públicas de abajo hacia arriba, en el que las comunidades se convierten en actores y no en simples receptores de políticas (Jaramillo, 2016).

Por lo tanto, el enfoque territorial para la construcción de paz permite la creación de condiciones más equitativas para las comunidades teniendo en cuenta las diferencias, desigualdades y necesidades presentes, en búsqueda de alternativas para la superación de estas. A pesar de que en todo el territorio se vivió el conflicto armado, con el enfoque territorial se justificó la focalización de acciones en los territorios rurales donde se cimentó la violencia y la guerra.

El cumplimiento de este enfoque se centró en el diseño de los Programas de Desarrollo con Enfoque Territorial, que permitió la creación de escenarios de interlocución y planeación conjunta entre los diversos actores del territorio (comunidades, empresa, Estado), a nivel municipal, local y regional. Los pactos resultantes de los escenarios de planeación buscan la transformación de las condiciones de los pobladores rurales en términos de reparación, reconciliación, verdad y acceso a derechos. El encuentro de diversos y contrarios actores posibilitó en algunos territorios, como lo veremos más adelante, escenarios de diálogo social de carácter intercultural como ejercicio de planificación.

Cabe señalar que estos escenarios de diálogo e interlocución, proyectados en la implementación del Acuerdo, han tenido un reto funda- 
mental en medio de la polarización política que tiene el país frente a la construcción de paz, desencuentro evidenciado en los resultados del Plebiscito por la Paz convocado antes de la firma del Acuerdo, donde a la pregunta: ¿Apoya usted el Acuerdo final para la terminación del conflicto y la construcción de una paz estable y duradera? la respuesta mayoritaria fue NO, con 50.21\% (6.431.376) mientras el SI obtuvo un $49,78 \%$ (6.377.482), lo que equivale a una diferencia de 53.894 votos.

Por otra parte, la discusión sobre el proceso efectivo de implementación también ha sido clave en la construcción de paz territorial, en general sobre el punto de Reforma Rural Integral-PDET y en específico sobre el proceso de implementación del Plan de Acción para la Transformación Territorial (PATR), lo que ha generado desconfianza por parte de las comunidades sobre el alcance de las proposiciones del documento para la transformación territorial. Por ejemplo, al analizar las tendencias del segundo informe entregado por el Instituto Kroc (1 diciembre 2016-31 mayo 2018), en el punto de Reforma Rural Integral es posible ubicar que el $50 \%$ de las proposiciones que hacen parte de este punto del Acuerdo de Paz no se han iniciado, el $45 \%$ cuenta con avance mínimo, el 3\% intermedio y el $2 \%$ con un avance completo.

Ahora bien, en el tercer informe publicado por el Instituto Kroc con corte a febrero 2019 (ver gráfico 1), se puede ubicar, para este mismo punto, que el estado de implementación es del $51 \%$ con avances mínimos, $8 \%$ intermedios y $3 \%$ completos, resaltando que, "siguen en pie los principales instrumentos para su implementación, tales como el fondo de tierras, los PDET, y la implementación de una serie de planes que apuntan a la inversión de bienes y servicios públicos rurales en municipios priorizados” (Instituto Kroc, 2019, p. 3). Al comparar ambos informes, es clave reconocer que hay un aumento en los porcentajes del proceso de implementación, de la siguiente manera: de 6\% en el mínimo, $5 \%$ en el intermedio y $1 \%$ en el completo. Sin embargo, es preocupante que el porcentaje, en aproximadamente ocho meses, no haya aumentado ni siquiera un $10 \%$ en las proposiciones. 
Gráfico 1. Porcentaje de implementación RRI. Dic. 2016-Feb. 2019

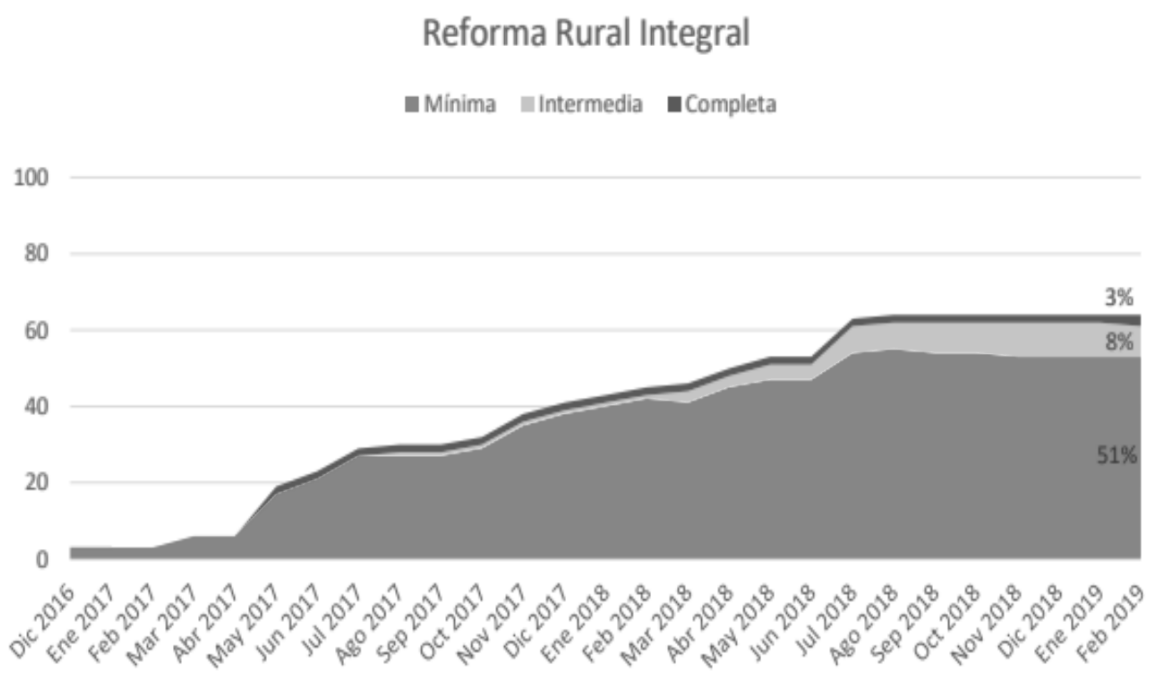

Fuente: Instituto Kroc (2019).

El poco avance en la implementación de la Reforma Rural Integral (RRI) evidencia dos problemas fundamentales: el primero se relaciona con acciones poco contundentes y coordinadas por parte de la institucionalidad responsable de la implementación del Acuerdo, probablemente atribuido al cambio de gobierno. Lo anterior deja como resultado, según los datos del Instituto Kroc para el 2019, que el 69\% de los compromisos del Acuerdo de Paz se están implementando, de los cuales el 23\% está en un estado de implementación completo, el 12\% intermedio y el 34\% mínimo; el $31 \%$ de proposiciones no ha iniciado su implementación. El segundo problema representa un reto fundamental para el Gobierno actual y tiene que ver con acciones y estrategia claras que permitan la implementación adecuada y con enfoque territorial del Acuerdo: ¿Cómo entender la potencialidad del diálogo social intercultural? 
El Acuerdo de Paz generó un reto al país en cuanto a la inclusión de los pobladores de esos territorios que sumidos en la violencia nunca habían contado con reales escenarios de participación, con lo cual afirma la importancia de enriquecer la inclusión política y forjar una ciudadanía crítica y dispuesta al diálogo social y a la construcción colectiva de nación (Jaramillo, 2016).

\section{Diálogo social: concepto y experiencia}

\section{Concepto: diálogo social intercultural}

De manera simplista, el diálogo es una práctica natural y cultural de la humanidad, "es un ejercicio humano por excelencia, muy sensible a las necesidades y prioridades definidas por las realidades locales, a las sutilezas del lenguaje y a lo intrincado de la memoria colectiva" (Pruitt y Thomas, 2008, p. 14). Por otro lado, el Diccionario de la lengua española lo define como "discusión o trato en busca de avenencia”.

Ahora bien, es importante considerar el aporte del diálogo en los procesos académicos y comprensivos de la realidad, en los que se destaca por "la apertura, la flexibilidad, la libertad y la actitud participativa [...] construye el conocimiento desde la realidad” (Santos, 1993, p. 26).

Es posible ubicar el ejercicio del diálogo en diferentes aspectos y ámbitos de la sociedad, como, por ejemplo, para gestionar conflictos y construir políticas públicas en el ejercicio democrático del Estado-Nación, que se cimenta en relaciones de poder y en diversos intereses, mientras en él confluyen ejercicios de toma de decisiones y reproducción de la sociedad. En consecuencia, el diálogo tiene relación estrecha con la democracia, a la vez que fortalece los ejercicios de la participación ciudadana propia del sistema de representación política y de su institucionalidad.

La democracia, por lo tanto, tiene como pilar fundamental el diálogo, bajo el principio de complejidad, pues "el devenir democrático está hecho de la 
resolución permanente de conflictos y desacuerdos. No se es democrático por alguna decisión en el tiempo; se construye democracia a diario, resolviendo diferencias en contextos de alta diversidad” (Toro, 2018, p. 4).

Es importante destacar que cada diálogo tiene su propósito y que este se ajusta a una situación problemática o a una necesidad en particular, con lo cual cobra vital importancia por dos aspectos: el primero es el déficit de la democracia, traducido en una cultura de participación y cooperación entre sociedad o actores resilientes y gobiernos democráticos efectivos; el segundo se relaciona con una ineficaz gobernabilidad que representa debilidad en la confianza pública y en el acompañamiento a las instituciones democráticas (Pruitt y Thomas, 2008).

En cuanto a la noción de diálogo social, este está profundizado en documentos internacionales (Unión Europea, Organización Internacional del Trabajo -OIT), en el lenguaje común y en los sistemas políticos, lo que podría suponer su imprecisión al momento de definirlo (Ermida, 2006). De manera general, podría decirse que en el contexto de las relaciones laborales se puede afirmar que

el diálogo social incluye a la negociación colectiva, a los mecanismos de información y consulta -institucionalizados o no- a los medios participativos y voluntarios de solución de conflictos de trabajo, a la participación -orgánica o inorgánica, en la empresa o en instancias sectoriales y nacionales-, y la concertación social, incluidos los pactos sociales o acuerdos marco. (Ermida, 2006, p. 57).

Para la OIT (2017), el diálogo social a nivel nacional hace referencia a la cooperación entre actores sociales, entre trabajadores y empleadores y el gobierno. Y según Ishikawa, “puede comprender una extensa variedad de cuestiones, desde las relaciones laborales hasta problemas sociales y económicos más generales” (2004, p. 1), en este, el gobierno puede ser actor o facilitador del diálogo. Es así que el diálogo social se ha convertido en un elemento para evaluar el buen gobierno de los 
países, ya que el diálogo de estos actores "en la formulación de políticas económicas y sociales cumple una función fundamental en la mejora de la democracia, la justicia social y la economía productiva y competitiva" (Ishikawa, 2004, p. 1).

De acuerdo con lo anterior, la concepción de diálogo social va relacionada con la gobernanza territorial enfocada en el empoderamiento de las comunidades en el ejercicio de gobierno, puesto que "ofrece la oportunidad a los actores sociales y a otros actores para que participen en la definición de su futuro" (Ishikawa, 2004, p.1). La gobernanza se puede definir como

la realización de relaciones políticas entre diversos actores involucrados en el proceso de decidir, ejecutar y evaluar decisiones sobre asuntos de interés público, proceso que puede ser caracterizado como un juego de poder, en el cual competencia y cooperación coexisten como reglas posibles; y que incluye instituciones tanto formales como informales. (Whittingham, 2010, p. 222).

Es por ello que el diálogo social es un medio para facilitar una interacción e intercambio constructivo entre diversos actores — con visiones $o$ intereses diferentes que pueden ser diversos $u$ opuestos ${ }^{1}-$ y llegar a consensos o acuerdos en aspectos territoriales, ambientales, laborales, económicos, sociales y políticos. Por lo tanto, "el diálogo social pretende facilitar una interacción constructiva con el fin de llegar a consenso/ compromiso social entre diferentes interlocutores de la sociedad" (Ishikawa, 2004, p. 1). Por lo tanto, será fundamental entender el diálogo social como un ejercicio que fomenta y fortalece la democracia par-

1 De acuerdo con lo que se ha adelantado desde el Instituto de Estudios Interculturales los diálogos entre diversos se desarrolla entre comunidades o actores que tienen posturas cercanas respecto a algún tema con incidencia en su comunidad. Sin embargo, al referirse entre opuestos son los actores en los que sus posturas son irreconciliables y muy lejanas para llegar a consensos, son los diálogos más complejos y que requiere rutas y un largo tiempo para encontrar puntos en común, a pesar de esto, hay experiencias de pactos comunitarios con actores opuestos para reconocer los derechos de cada uno. 
ticipativa que, mediante concesiones y entendimiento mutuos, busca solucionar problemas o gestionar conflictos, y no por imposición de un punto de vista e intereses de una sola parte.

Por lo tanto, será necesario considerar al diálogo social como un elemento central para fomentar y fortalecer la gobernanza de los actores territoriales, toda vez que a partir de la gestión de conflictos y la superación de diferencias fomenta el desarrollo rural, la planeación territorial y la construcción de paz, dado que "una paz sostenible es aquella que empodera a las personas y las ayuda a adquirir habilidades y crear instituciones para gestionar en forma pacífica los diferentes y a veces conflictivos intereses” (Pruitt y Thomas, 2008, p. 13).

Por otro lado, Xavier Mínguez (2015) plantea la necesidad de fomentar espacios de acercamiento, diálogo y colaboración entre actores opuestos por intereses políticos e ideológicos, lo que permite promover una democracia pluralista basada en los derechos humanos, para el desarrollo sostenible y la construcción de paz territorial, dando insumos a lo que se conoce como metodología para el diálogo entre contrarios.

De acuerdo con Pruitt y Thomas (2008), para desarrollar el ejercicio de la democracia participativa se deben fortalecer las siguientes capacidades: resolver conflictos de forma pacífica, cooperar trascendiendo líneas políticas partidarias, desarrollar una agenda incluyente para la acción y fortalecer la participación ciudadana. Se reconoce, además, que el diálogo enfrenta cinco desafíos: ocuparse de la complejidad, coordinar el significado, producir innovación, posibilitar deliberación y producir resultados sostenibles. Además, los procesos de diálogo cumplen las siguientes características: inclusividad, apropiación compartida, aprendizaje, humanidad y una perspectiva a largo plazo.

El diálogo social posibilita la deliberación y la toma de decisiones. "Estas decisiones conllevan importantes consecuencias y en ese proceso, en definitiva, los valores cumplen un rol principal (...) cuando 
se designan derechos individuales en favor de la seguridad, en asuntos medioambientales en favor del desarrollo económico" (Pruitt y Thomas, 2008, p. 40).

Para emplear el diálogo social se necesita analizar el contexto, utilizando métodos adecuados para proponer alternativas innovadoras. De acuerdo con la oIT, en las relaciones laborales este contexto se puede realizar en diferentes niveles del ejercicio de diálogo, ocasionando variación en los impactos de acuerdo a la intensidad del proceso. En relación a lo anterior, se destaca el intercambio de información como proceso elemental para el sostenimiento del diálogo, que no implica acercamiento de actores pero sí tener elementos para ejercicio de encuentros, conviertiéndose en un punto de partida.

Un paso posterior implica el diálogo para la consulta, en el que los interlocutores comparten información y se comprometen más a fondo con los intereses o aspectos planteados. Finalmente, en el punto más alto del diálogo se ubica la negociación, en la que se destaca la negociación colectiva y la concertación política (Ishikawa, 2004, p. 3). Sin embargo, se asevera que cada uno de estos momentos se puede cruzar y retroalimentar para llevar de manera adecuada el diálogo.

En contraparte, en contextos rurales, para el caso colombiano, los escenarios de diálogo social son posibles por cuanto existe el reconocimiento de la validez y la legitimidad del “otro", esto es, el campesino, indígena, afrodescendiente, empresarios, mujeres. A través de la construcción de relaciones de confianza que posibiliten escenarios de encuentro tanto para la resolución de conflictos como para la construcción de proyectos conjuntos y la reconciliación, estos escenarios reconocen las territorialidades y gobernanza de las comunidades. Para este caso, el Instituto de Estudios Interculturales (IEI) ha trabajado el diálogo social con enfoque intercultural. 
Ahora bien, es importante recalcar la noción de diálogo dialogal que posibilita la construcción de paz, comprendido desde Panikkar (2006), lo que presupone la capacidad de dimensionar nuestra cultura a sus justas proporciones en relación con las demás culturas del mundo (interculturalidad), reconociendo que no existen culturas superiores ni inferiores, y que no se trata de "con-vencer" al otro, sino por el contrario, entender y comprender los mundos propios, a partir de la confianza mutua y el reconocimiento de la diferencia.

La interculturalidad, como una propuesta política, "se centra en la calidad del proceso de interrelación y encuentro entre distintos” (Duarte, Duque y Quintero, 2018, p. 29), además, supera la simple relación entre culturas. Se distingue por ser una respuesta al colonialismo, pues mediante ejercicios normativos, políticos y culturales genera discriminación positiva de las comunidades excluidas, como la aplicación de la multiculturalidad. De esta manera, la interculturalidad rescata la capacidad de agencia de las comunidades locales rurales indígenas, campesinas y afrocolombianas, para planear conjuntamente el futuro y construir sobre máximos comunes. En tal sentido, "la interculturalidad es un principio ideológico (...), que le apunta a la transformación de las actuales estructuras, instituciones y relaciones de la sociedad, con miras a conformar poderes locales alternativos” (Walsh, 2005, p. 42).

La interculturalidad, como un proceso constante y de largo plazo en escenarios específicos, ha posibilitado "la construcción de complejas relaciones, negociaciones e intercambios culturales de múltiples vías" (Walsh, 2005, p. 45), por lo tanto, se ha convertido en la oportunidad para generar convergencias políticas alternativas al poder dominante, en la búsqueda de transformar y construir estructuras, relaciones e instituciones que reconozcan el pensar diferente y las apuestas comunitarias para la incidencia local y regional.

De acuerdo con el Consejo Regional Indígena del Cauca (CRIC), la interculturalidad es la posibilidad del diálogo entre culturas (citado en 
Walsh, 2009). Se podría decir que este concepto tiene amplia cabida en los contextos de constitución de Estado-nación en América Latina, en especial en la década de los 90 ,

en atención a la diversidad étnico-cultural (...) reconocimientos jurídicos y de una necesidad cada vez mayor de promover relaciones positivas entre distintos grupos culturales, de confrontar la discriminación, el racismo y la exclusión, de formar ciudadanos conscientes de las diferencias y capaz de trabajar conjuntamente en el desarrollo del país. (Walsh, 2009, p. 2).

Para este análisis, la interculturalidad

va más allá del contacto o interacción entre pueblos y se entiende como una postura política y ética, se centra en la calidad del proceso de interrelación y encuentro entre distintos (...) Las relaciones interculturales son complejas, implican negociaciones e intercambios de culturas, en los cuales no existe una supremacía de una visión de mundo sobre otra. (Rodríguez, Espitia, Ante, Muñoz y Duarte, 2017, p. 55).

Partimos de que los lineamientos de diálogo social se sustentan en la definición de construcción de paz positiva, que implica la transformación de los conflictos de forma constructiva en diferentes ámbitos; político, social, económico y cultural, con el fin de conseguir la armonía de la persona, del grupo, con ella misma, con los otros y con la naturaleza. Entre los criterios para el diálogo social intercultural se pueden ubicar: i. búsqueda de intereses y puntos de encuentro, elementos comunes entre los actores que sirvan de punto de partida para establecer diálogo; ii. planear el diálogo no como renuncia de los desacuerdos presentes, sino como un nuevo compromiso que facilite la gestión de conflictos.

De acuerdo con la investigación aplicada desde el IEI, es posible ubicar como pasos metodológicos para el diálogo social intercultural los siguientes: 
- Análisis de la situación de las partes desde afuera (contacto inicial).

- Preparación de los actores del conflicto.

- Exposición de cada una de las partes sobre su visión del conflicto (catarsis).

- Poner las reglas de juego y la forma de procedimiento para realizar la discusión (arreglos o acuerdos para la mediación).

- Exposición de los intereses de cada uno de los actores.

- Proposición de las formas de solución en conjunto y escoger la más adecuada (solución participativa de los problemas).

- Establecimiento de compromisos a futuro, acuerdos, sanciones, entre otros.

- Establecimiento/definición conjunta de mecanismos de seguimiento y verificación de mecanismos de acuerdos

Estos elementos son esenciales para un diálogo asertivo, pero también es clave exponer que los pasos pueden variar de acuerdo al contexto, alcance y expectativa de los actores que participan en él. Finalmente, en esta metodología es clave reconocer que muchos de estos ejercicios han posibilitado la planeación territorial desde los acuerdos colectivos y la gestión de conflictos, así la cultura del diálogo altere las relaciones de poder. Esta planeación corresponde a lo que Pruitt y Thomas (2008) han denominado una perspectiva de largo plazo necesaria para encontrar soluciones sostenibles, afirmando que en "el diálogo, se trata de emplear el tiempo de un modo diferente, en el sentido de darse cuenta de que no hay soluciones rápidas" (Pruitt \& Thomas, 2008, p. 50). Lo anterior muestra la necesidad de fortalecer y potencializar las capacidades — destrezas y aptitudes- para el diálogo, la negociación y la concertación. 


\section{Experiencia del Instituto de Estudios Interculturales}

El IEI de la Pontificia Universidad Javeriana Cali, en su misión de consolidarse como puente para el diálogo y un instrumento para la paz, ha fomentado escenarios de encuentro e interlocución entre actores diversos con distintas visiones e intereses en los territorios rurales.

Para tal fin, de manera estratégica le apuesta al diálogo social con enfoque intercultural, donde los diferentes actores rurales (campesinos, indígenas y afrodescendientes), el sector privado y las instituciones estatales, buscan la gestión pacífica de conflictos, como también la concertación de acciones que fomenten el desarrollo rural social, ambiental y económicamente sostenible, en aras de la construcción de paz.

El trabajo realizado por el IEI en más de siete años de investigación e incidencia ha tenido impacto a nivel nacional. En él se destaca el acompañamiento al diálogo social enfocado en la construcción de principios de convivencia y reconciliación con procesos sociales, comunitarios, sector empresarial y entidades estatales en la región del suroccidente colombiano, concretamente en los departamentos de Cauca, Nariño, Valle del Cauca, Huila, Putumayo y Caquetá. La puesta en marcha de este ejercicio investigativo encaminado al diálogo social intercultural se ha realizado con organizaciones sociales con gran incidencia regional. como el CRIC, la Asociación de Cabildos Indígenas del Norte del Cauca (ACIN), la Comunidad Misak, el Comité de Integración del Macizo Colombiano (CIMA), la Federación Nacional Sindical Unitaria Agropecuaria (FEnsuAgro-CUT), el Proceso de Unidad Popular del Suroccidente Colombiano (PUPSOC), la Corporación Consejo Comunitario de Organizaciones de la Cuenta Alta del Río Patía (CORPOAFro) y la Unidad de Organizaciones Afrocaucanas (UOAFROC).

Así mismo, las metodologías de diálogo social han sido trabajadas con el sector agroindustrial, tales como ingenios azucareros y organizaciones como la Asociación de Cultivadores de Caña de Azúcar de Colombia 
(ASOCAÑA) y la Asociación Colombiana de Productores y Proveedores de Caña de Azúcar (PROCAÑA). Se destacan por el lado de las instituciones estatales el acompañamiento técnico y profesional al Ministerio de Agricultura y Desarrollo Rural (MADR); Ministerio del Interior; el liquidado INCODER, ahora Agencia Nacional de Tierras (ANT); y la Agencia de Desarrollo Rural (ADR).

A partir de los procesos de investigación aplicada adelantados por el IEI, es posible señalar algunas estrategias de acompañamiento para el diálogo social intercultural, que varían de acuerdo al contexto, a los actores y sus intereses. Por lo tanto, se pueden ubicar cinco ámbitos de aplicabilidad de las estrategias:

1) Acompañamiento al Estado y a las comunidades en la gestión de los conflictos territoriales.

2) Acompañamiento a escenarios de negociación e interlocución entre comunidades indígenas, campesinas y afrocolombianas [comunidad-comunidad], con el Gobierno nacional [comunidad-sector público], y con la empresa privada [comunidad-empresa].

3) Diseño y construcción de metodologías de diálogo social para la planificación, construcción de paz y gobernanza territorial.

4) Apoyo y asesoría en la formulación de políticas para el sector rural a través de metodologías participativas.

De manera más específica, los siguientes escenarios son ejemplo de los anteriores ítems: i. Fortalecimiento de Mesas de Negociación del CRIC y el Gobierno nacional para la construcción de estrategias de negociación y diálogo, y encuentro entre los actores en torno de los derechos humanos, consecuencias del conflicto armado, conflictos territoriales, entre otros. ii. Asesorías en la construcción de un método de relacionamiento de diálogo intercultural con las Corporaciones Autónomas Regionales del Valle y Cauca. iii. Construcción e implementación de una estrategia común de 
negociación entre autoridades indígenas y directivos de los ingenios azucareros, iv. Acompañamiento al Gobierno nacional en la gestión de conflictos interculturales, tales como la Mesa de la Asociación Nacional de Usuarios Campesinos de Colombia (ANUC), Mesa Afrocaucana y Mesa Campesina del Cauca. v. Acompañamiento a la Oficina del Alto Comisionado para la Paz en el diseño de una propuesta metodológica de diálogo social en pilotos de paz territorial. vi. Espacios de cooperación y diálogo entre el sector agroindustrial y el pueblo nasa de los municipios de Corinto, Caloto y Toribío en la subregión del Norte del Cauca. vii. Ejercicios metodológicos en clave de diálogo social intercultural y de diálogos improbables, enfocados en la construcción de principios de convivencia y reconciliación.

Además de lo anterior, como resultado de los procesos de investigación se ha innovado en estrategias pedagógicas y didácticas para comprender el diálogo social intercultural como una herramienta central en la construcción de políticas públicas, lo que ha permitido un paso fundamental en la generación de condiciones para la participación de los actores rurales en escenarios de planeación territorial. Se destacan juegos de roles como: parqués, intercultural, coaching de negociación y debates entre contrarios.

Por otra parte, es importante mencionar el acompañamiento realizado por el IEI desde la línea de investigación movimientos sociales y construcción de paz en espacios de incidencia, veeduría y seguimiento de las organizaciones de la sociedad civil a la política pública de construcción de paz territorial. En ese sentido, se han acompañado apuestas de construcción y planificación territorial en el marco de la implementación del Acuerdo de Paz como lo es el PDET, que tuvo como eje central el diálogo y la cimentación de consensos para la construcción de las diferentes iniciativas. Este acompañamiento ha permitido la construcción de metodologías, asesorías a la institucionalidad responsable y trabajo articulado con las organizaciones sociales para la garantía del derecho a la paz y la reconciliación en los territorios rurales. 


\section{PDET Alto Patía y Norte del Cauca}

Teniendo en cuenta el Decreto 893 de 2017, el PDET es un instrumento de reconciliación en el que todos los actores trabajan en la construcción del bien supremo de la paz. A partir de la formulación e implementación de este programa se viabilizará la implementación del punto 1. Reforma Rural Integral, con todos sus lineamientos, en los municipios priorizados para tal fin, pues la RRI busca la transformación estructural del campo y crear condiciones de bienestar para la población rural. También aportará a los otros puntos del Acuerdo, teniendo en cuenta que

los PDET implican disponer efectivamente de un instrumento para que los habitantes del campo, las comunidades, los grupos étnicos y todos los involucrados en el proceso de construcción de paz en las regiones, junto al Gobierno Nacional y las autoridades públicas, construyan planes de acción concretos para atender sus necesidades, de acuerdo al enfoque territorial acordados entre todos. (Decreto 893 de 2017).

Conforme con el punto 1.2.1 del Acuerdo de Paz firmado entre el Gobierno y las FARC-EP (p.21), el objetivo de los PDET es lograr la transformación estructural del campo y el ámbito rural y un relacionamiento equitativo entre la ciudad y el campo, con el fin de asegurar:

1) El bienestar y el buen vivir de la población en zonas rurales —niños y niñas, hombres y mujeres - haciendo efectivos sus derechos políticos, económicos, sociales y culturales, y revirtiendo los efectos de la miseria y el conflicto.

2) La protección de la riqueza pluriétnica y multicultural para que contribuya al conocimiento, a la organización de la vida, a la economía, a la producción y al relacionamiento con la naturaleza.

3) El desarrollo de la economía campesina y familiar (cooperativa, mutual, comUNAL, micro empresarial y asociativa solidaria) y de formas propias de producción de [los pueblos, comunidades y grupos étnicos], mediante el acceso integral a la tierra y a bienes y servicios productivos y sociales. 
Los PDET intervendrán con igual énfasis en los espacios interétnicos e interculturales para que avancen efectivamente hacia el desarrollo y la convivencia armónica.

4) El desarrollo y la integración de las regiones abandonadas y golpeadas por el conflicto, implementando inversiones públicas progresivas, concertadas con las comunidades, con el fin de lograr la convergencia entre calidad de vida rural y urbana, y fortalecer encadenamiento entre la ciudad y el campo.

5) El reconocimiento y la promoción de las organizaciones de las comunidades, incluyendo a las organizaciones de mujeres rurales para que sean actores en primera línea de la transformación estructural del campo.

6) Hacer del campo colombiano un escenario de reconciliación en el que todos y todas trabajan alrededor de un propósito común, que es la construcción del bien supremo de la paz, derecho y deber de obligatorio cumplimiento.

Para la implementación del PDET, la Agencia de Renovación del Territorio (ART) tendrá un papel fundamental, focalizando su acción en 170 municipios de 16 subregiones en todo el país. Los municipios priorizados por las partes negociadoras cumplieron los siguientes aspectos: i) Altos niveles de pobreza, en particular de pobreza extrema, ii) Alto grado de afectación del conflicto, iii) Debilidad de la institucionalidad administrativa y de la capacidad de gestión y, iv) Presencia de cultivos de uso ilícito y de otras economías ilegales.

El PDET, por lo tanto, fue propuesto para definir las líneas de acción en la formulación de una visión del territorio que permitiera su transformación a 10 años, a partir del diagnóstico del territorio elaborado por las comunidades junto con varios enfoques: enfoque territorial que reconozca las características socio-históricas, culturales, ambientales y productivas del territorio y sus necesidades; enfoque diferencial para incorporar la perspectiva étnica y cultural de los pueblos; enfoque repara- 
dor y un enfoque de género que reconozca las necesidades particulares de las mujeres rurales.

El instrumento PDET es trascendental, no solo para la implementación de los mencionados puntos de la RRI (acceso y uso de la tierra y Planes Nacionales), sino también de otros puntos del Acuerdo Final tales como Participación Política (Punto 2 del Acuerdo), Fin del Conflicto (Punto 3 del Acuerdo), Solución Al Problema de las Drogas Ilícitas (Punto 4 del Acuerdo) y Víctimas (Punto 5 del Acuerdo), en la medida que son los mismos actores de las regiones quienes determinan con precisión los aspectos que en cada uno de estos puntos se requieren. (Decreto 893 de 2017).

La región del Alto Patía y Norte del Cauca, constituida en el marco del PDET, está conformada por un total de 24 municipios de los departamentos del Valle del Cauca, Cauca y Nariño, de la manera que se aprecia en a continuación:

\section{Tabla 1. Municipios priorizados por departamento PDET Alto Patía y Norte del Cauca}

\begin{tabular}{|c|l|}
\hline Departamento & \multicolumn{1}{|c|}{ Municipio } \\
\hline Valle del Cauca & Florida, Pradera. \\
\hline Cauca & $\begin{array}{l}\text { Miranda, Corinto, Caloto, Toribío, Jambaló, } \\
\text { Santander de Quilichao, Buenos Aires, Suárez, } \\
\text { Caldono, Piendamó, Morales, Cajibío, El Tam- } \\
\text { bo, Argelia, Patía, Balboa, Mercaderes }\end{array}$ \\
\hline Nariño & $\begin{array}{l}\text { Leiva, El Rosario, Policarpa, Cumbitara, } \\
\text { Los Andes }\end{array}$ \\
\hline
\end{tabular}

Fuente: Elaboración propia, Instituto de Estudios Interculturales (2019). 
En el mapa 1, se puede reconocer la presencia de organizaciones sociales en la subregión PDET, y ubicar diferentes iniciativas de incidencia, ordenamiento y control territorial, como son resguardos indígenas, titulaciones colectivas y aspiraciones de zonas de reserva campesina de comunidades indígenas, afrocolombianas y campesinas respectivamente.

La presencia territorial de las comunidades rurales demuestra un alto índice de actividades comunitarias, reivindicativas, políticas y económicas en el territorio, que permiten mapear ejercicios de diálogo social intercultural en clave de incidencia y de planeación territorial.

De acuerdo con la proyección del Departamento Nacional de Estadística (DANE, 2018), la región del Alto Patía y Norte del Cauca tiene un total de 788456 habitantes, de los cuales el 64\% es población rural y el 36\% urbana; y su extensión territorial es de 12568 km² (Agencia de Renovación del Territorio, 2018). De acuerdo con datos del Departamento Nacional de Planeación (DNP), en esta región las categorías de ruralidad evidencian un alto porcentaje de rural y rural disperso: 54\% y $21 \%$ respectivamente.

Tabla 2. Categorías de ruralidad Alto Patía y Norte del Cauca

\begin{tabular}{|l|c|c|c|c|c|c|}
\cline { 2 - 7 } \multicolumn{1}{c|}{} & \multicolumn{2}{c|}{ Alto Patía } & \multicolumn{2}{c|}{ Total PDET } & \multicolumn{2}{c|}{ Nacional } \\
\hline Ciudades y aglomeraciones & 2 & $8 \%$ & 12 & $7 \%$ & 117 & $11 \%$ \\
\hline Intermedios & 4 & $17 \%$ & 28 & $1,7 \%$ & 314 & $28 \%$ \\
\hline Rural & 13 & $54 \%$ & 71 & $42 \%$ & 373 & $34 \%$ \\
\hline Rural Disperso & 5 & $21 \%$ & 58 & $34 \%$ & 318 & $27 \%$ \\
\hline Total & $\mathbf{2 4}$ & $\mathbf{1 0 0} \%$ & $\mathbf{1 7 0}$ & $\mathbf{1 0 0} \%$ & $\mathbf{1 . 1 2 2}$ & $\mathbf{1 0 0} \%$ \\
\hline
\end{tabular}

Fuente: Misión Transformación del campo colombiano. DNP (2014). 


\section{Mapa 1. Presencias sociales región PDET Alto Patía y Norte del Cauca}

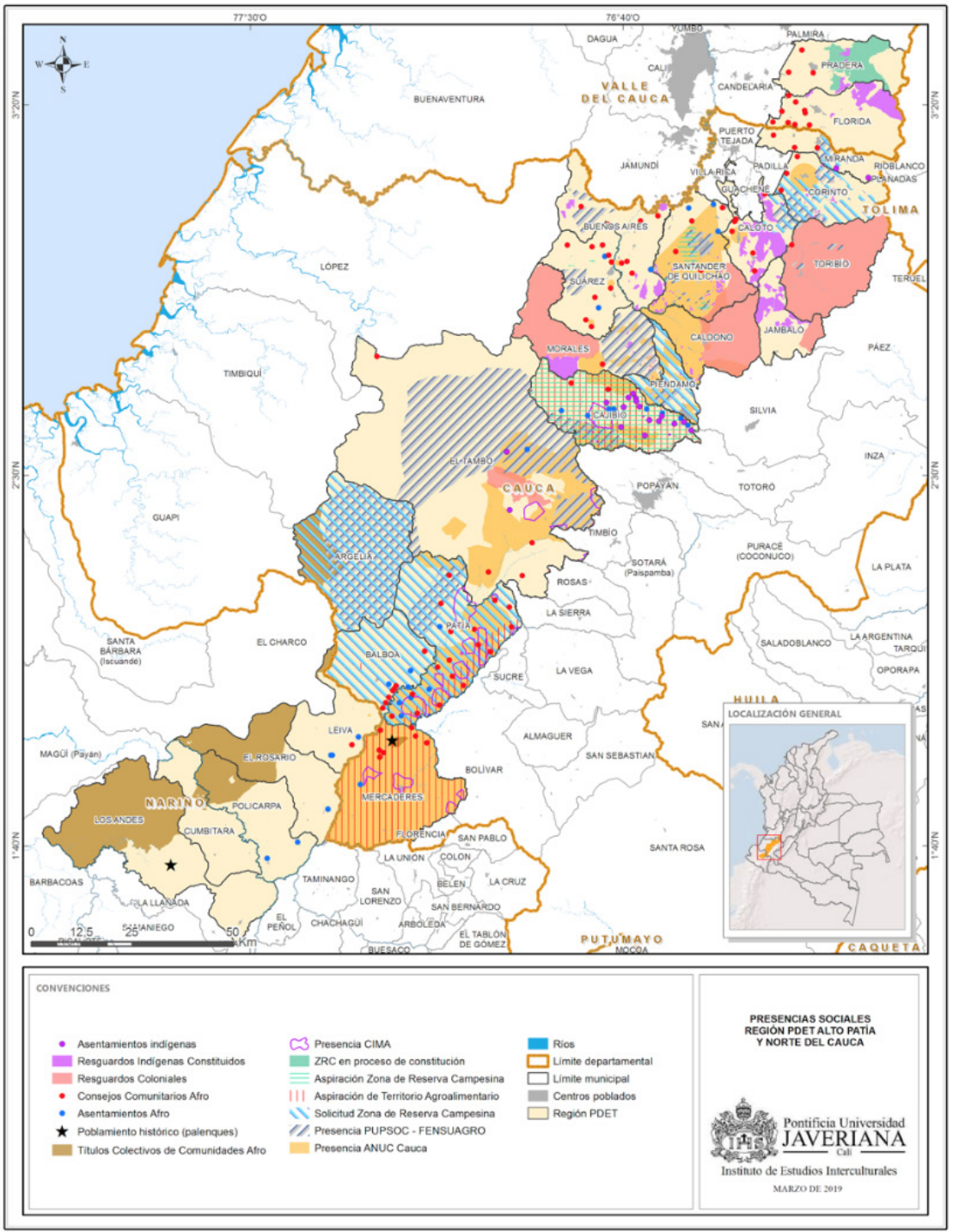

Fuente: elaboración propia, Instituto de Estudios Interculturales (2019) 
Su ubicación permite caracterizar la región como un corredor biológico e hídrico estratégico del que hacen parte tres cuencas: la del río Patía, la cuenca geográfica del río Cauca y la cuenca del río San Juan de Micay. En ella se presentan todos los pisos térmicos, "con sus respectivos relieves y condiciones climáticas particulares, es decir, contiene desde planicies aluviales hasta montañas pertenecientes a la Cordillera Central y Occidental" (Agencia Renovación del Territorio, 2018, p. 6) Además, en la región se reconocen varias figuras de ordenamiento territorial ambiental, tales como parques nacionales naturales y áreas de reserva forestal de Ley Segunda.

La metodología de construcción del PDET desarrollada y propuesta por la ART fue crucial, pues mostró al país que era posible la participación real de la ciudadanía en la fase de formulación y creación de acuerdos para la transformación territorial.

Para tal fin se distinguieron tres etapas: 1) la veredal-comunitaria en la que se firmó el Pacto Comunitario para la Transformación Regional (PCTR); 2) la municipal, en la que se firmó el Pacto Municipal para la Transformación Regional (PMTR); y 3) la firma del Plan de Acción para la Transformación Regional (PATR). La estructura del PDET en su construcción de planeación fue desarrollada bajo la metodología de abajo hacia arriba o bottom-down; que consiste en "partir de los comportamientos concretos en el nivel donde existe el problema para construir la política pública poco a poco, con reglas, procedimientos y estructuras organizativas" (Röth, 2003, p. 122).

Dentro de este proceso participaron las comunidades campesinas, indígenas y afro; mujeres, víctimas y en algunos casos personas en proceso de reincorporación. Así mismo, otros sectores privados con presencia en los municipios priorizados en los PDET. Atendiendo a la metodología, los escenarios de participación fueron convocados por la ART en cada uno de los niveles mencionados. 
De acuerdo con el Decreto 893 de 2017, los PATR son la única herramienta para la Reforma Rural Integral que involucra todos los niveles del ordenamiento territorial, sus actores y recursos. Para la formulación del PDET se tuvieron en cuenta ocho pilares: i. Educación y primera infancia rural; ii. Infraestructura y adecuación de tierras; iii. Ordenamiento social de la propiedad y uso del suelo; iv. Reactivación económica y producción agropecuaria; v. Reconciliación, convivencia y construcción de paz; vi. Salud rural; vii. Sistema para la garantía progresiva al derecho a la alimentación; y, viii. Vivienda rural, agua potable y saneamiento básico rural.

Ahora bien, para la región Alto Patía y Norte del Cauca se formularon 24 Pactos Comunitarios para la Transformación Regional, 3 Pactos Étnicos y 24 Pactos Municipales para la Transformación Regional. A nivel municipal fueron cerca de 4691 iniciativas para los 24 municipios, que luego de la revisión jurídica de la ART quedaron en 4382, de las cuales fueron deshabilitadas 18, para que en total se contara con un total de 4364 iniciativas. En la tabla 3 es posible reconocer el número de iniciativas por cada uno de los municipios:

\section{Tabla 3. Número de iniciativas por municipio PDET Alto Patía y Norte del Cauca}

\begin{tabular}{|c|c|c|}
\hline Municipio & $\begin{array}{c}\text { No. de iniciativas } \\
\text { iniciales }\end{array}$ & $\begin{array}{c}\text { No. de Iniciati- } \\
\text { vas finales }\end{array}$ \\
\hline Argelia & 232 & 231 \\
\hline Balboa & 163 & 163 \\
\hline Buenos Aires & 194 & 194 \\
\hline Cajibio & 181 & 180 \\
\hline Caldono & 368 & 367 \\
\hline Caloto & 181 & 178 \\
\hline
\end{tabular}




\begin{tabular}{|c|c|c|}
\hline Corinto & 166 & 166 \\
\hline Cumbitara & 233 & 232 \\
\hline El Rosario & 172 & 172 \\
\hline El Tambo & 141 & 141 \\
\hline Florida & 163 & 162 \\
\hline Jambaló & 115 & 115 \\
\hline Leiva & 203 & 202 \\
\hline Los Andes & 147 & 147 \\
\hline Mercaderes & 180 & 179 \\
\hline Miranda & 193 & 192 \\
\hline Morales & 197 & 196 \\
\hline Patía & 157 & 155 \\
\hline Piendamó & 144 & 144 \\
\hline Policarpa & 184 & 184 \\
\hline Pradera & 138 & 138 \\
\hline Santander de & 229 & 227 \\
\hline Quilichao & 148 & 146 \\
\hline Suárez & 153 & 4.364 \\
\hline Toribío & 4.382 & \\
\hline Total & & 153 \\
\hline
\end{tabular}

Fuente: Instituto de Estudios Interculturales (2019).

De acuerdo con las anteriores cifras, dentro de los cinco municipios que cuentan con mayores iniciativas en los pactos municipales destacan: en el departamento del Cauca, los municipios de Caldono, Santander de Quilichao y Argelia; y en el departamento de Nariño los municipios de Cumbitara y Leiva. Para el caso de esta región es importante destacar que de las 4364 iniciativas las de mayor número corresponden al pilar de educación y primera infancia rural, con una total de 1024, seguido del de reactivación económica y producción agropecuaria, con 1018, y en tercer lugar el de reconciliación, convivencia y construcción de paz, con 544 iniciativas. El pilar con menor número de iniciativas corresponde a sistema para la garantía progresiva al derecho a la alimentación, con 242. 


\section{Gráfico 2. Total iniciativas por pilar subregión Alto Patía y Norte del Cauca}

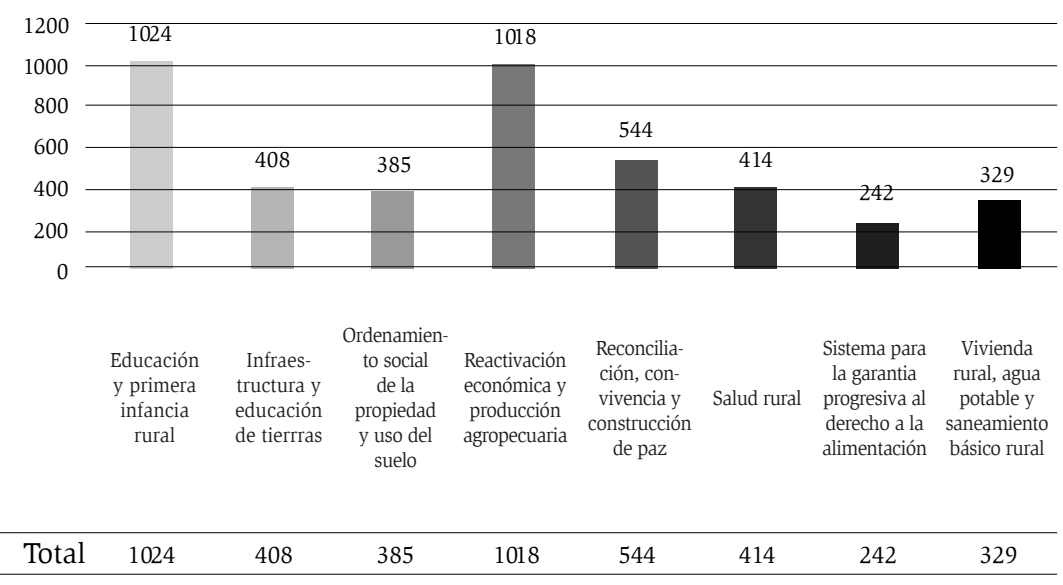

Fuente: Instituto de Estudios Interculturales (2019).

Lo anterior pone en evidencia un problema central en la región: la pertinencia, acceso y calidad de la educación en los diferentes niveles formativos de las comunidades rurales; del mismo modo, está presente la necesidad urgente de avanzar en consolidar proyectos y apuestas económicas que vinculen a la agricultura familiar y permitan el desarrollo desde el enfoque territorial. Finalmente, la necesidad de reconocer, apoyar e incentivar las distintas iniciativas de construcción de paz ubicadas en el pilar de reconciliación que adelantan las comunidades rurales. Sin embargo, es importante considerar el peligro de la reconfiguración del conflicto armado y el aumento sistemático de los líderes y lideresas asesinados y amenazados en la región.

Ahora bien, al analizar el momento subregional con la firma del PATR es importante mencionar que para el Alto Patía y Norte del Cauca se consolidaron 84 iniciativas, que "serán revisadas, viabilizadas técnicamente y priorizadas por los sectores competentes a nivel nacional y territorial, teniendo en cuenta las políticas públicas, la normatividad 
vigente y las particularidades del territorio" (Agencia de Renovación del Territorio y Presidencia de la República, 2018, p. 12).

Las iniciativas que esperan la transformación regional se pueden ubicar de manera cuantitativa de acuerdo a cada pilar, como se observa en el gráfico 3.

\section{Gráfico 3. Iniciativas por pilar en el Plan de Acción para la Transformación Regional Alto Patía y Norte del Cauca}

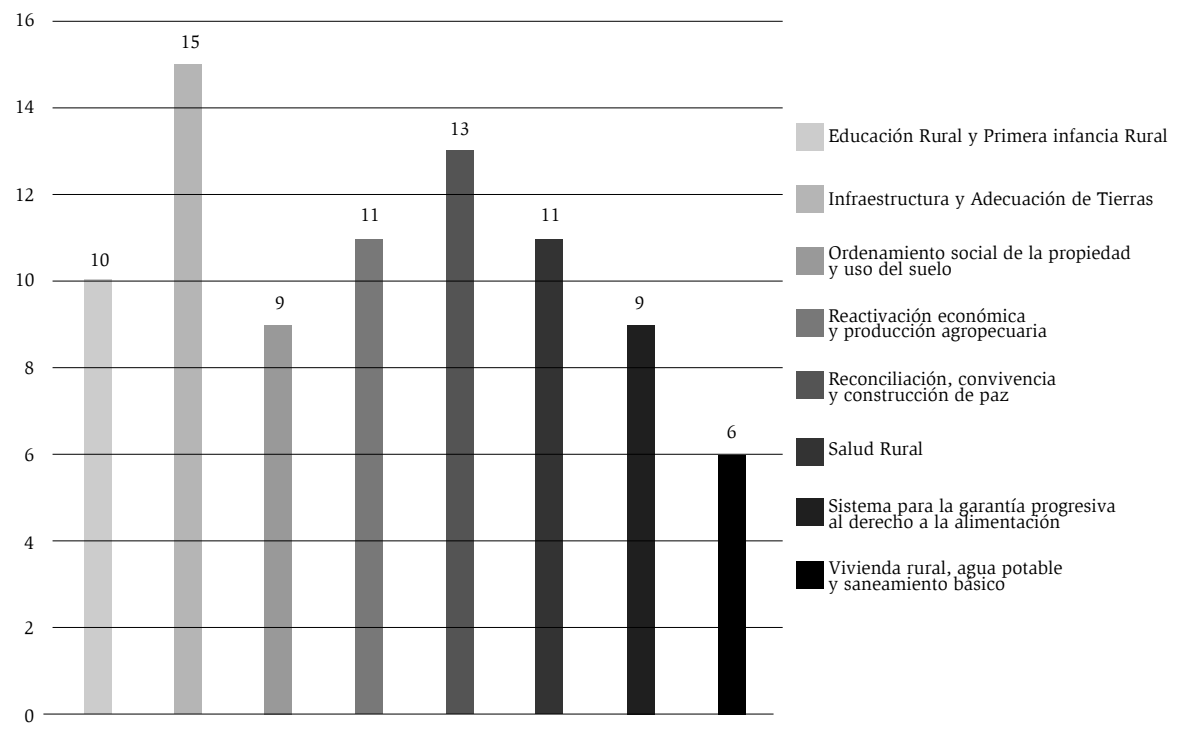

Fuente: Instituto de Estudios Interculturales (2019).

El pilar de infraestructura y adecuación de tierras tuvo mayor cantidad de iniciativas acordadas, con un número total de 15 , seguido del de reconciliación y construcción de paz con 13. En suma, el PDET para el Alto Patía y Norte del Cauca cuenta con un total de 4448 iniciativas de corte municipal y regional. 
Hay que mencionar que la metodología propuesta para el PDET instó y garantizó la participación efectiva de las comunidades rurales que, por primera vez en muchos años, aportaron en la construcción de una política pública propuesta directamente desde el nivel veredal (local). Sin embargo, los resultados de la cantidad de iniciativas no solamente muestran el acercamiento a un diagnóstico del territorio a la luz de problemáticas, necesidades y posibilidades que en muchos casos se entienden como "lista de mercado”, sino que evidencian también el reto de que sean tenidas en cuenta en la implementación en cada uno de los municipios, sobre todo en las futuras elecciones territoriales y departamentales. Se debe agregar que será clave conocer cómo será la priorización de las iniciativas por las entidades locales y departamentales responsables de definir el tipo de enfoque territorial y el modelo de desarrollo rural que se posicionará.

Si bien el diálogo social hizo parte del proceso PDET en las diferentes escalas de la formulación, es importante analizar y reflexionar sobre la necesidad de posicionarlo como elemento constitutivo en el proceso de implementación de las iniciativas.

\section{El diálogo social intercultural, un reto para la construcción de paz territorial: PDET}

Tal como se ha visto con anterioridad, la implementación del Acuerdo de paz en su generalidad, y en particular el PDET, supone un elemento central para lograr la transformación positiva de los territorios rurales: la apertura y acceso a derechos en el marco de la Reforma Rural Integral. Sin embargo, el desarrollo de estas iniciativas a nivel municipal y regional, en términos participativos, financieros y políticos no es muy claro. Los retos que a continuación de exponen corresponden a la implementación del PDET, pues a pesar de reconocer elementos constitutivos de la formulación y diseño, en la actualidad se están discutiendo y adelantando estrategias para su implementación. 
Lo anterior supone la necesidad de construir o consolidar escenarios de incidencia, seguimiento y veeduría sobre la cantidad de iniciativas que salieron del seno de las comunidades rurales, como también instar a adelantar esfuerzos institucionales para articulaciones reales en los territorios.

En el marco de este análisis se proponen cuatro tipos de retos teniendo en cuenta la realidad territorial de la región Alto Patía y Norte del Cauca: el primero es el reto político, enmarcado en las acciones que deben ser tenidas en cuenta en el contexto actual, en el que cualquier decisión será crucial para garantizar la implementación. Luego están los retos institucionales, caracterizados por funciones y articulaciones entre las instituciones públicas responsables de la implementación del PDET y del Acuerdo de paz. Más adelante se mencionan los retos participativos, donde se destacan los esfuerzos de instituciones de carácter público y privado nacionales y territoriales, para no perder el espíritu participativo con el que se cimentó el acuerdo. Finalmente, el último reto es el comunitario, que presenta los esfuerzos que hacen las comunidades para el ejercicio de veeduría y seguimiento a la política pública.

\section{Retos políticos}

1. Comprender el diálogo social intercultural como un elemento constitutivo de la gestión pública, no solamente de carácter nominal. En algunas ocasiones el diálogo social constituye un "simulacro de la democracia", en el que a pesar de constituir escenarios de interlocución y negociación de actores se agotan políticamente las partes y se subsume dentro de un discurso tecnocrático que no permite una adecuada participación.

2. Reconocer el enfoque territorial más allá de la implementación de políticas de intervención económica, lo cual implica la posibilidad de fortalecer la institucionalidad más allá del papel del Estado, ubicándola en la noción de lo público y el bien común, permitiendo el fortalecimiento de los procesos territoriales y potencializando su accionar.

3. Fomentar el diálogo social intercultural como un ejercicio de planeación de abajo hacia arriba, de cara a los nuevos mandatarios en lo local y de- 
partamental, en el que sea clara la metodología de implementación de las iniciativas y permita la articulación de actores e instituciones.

4. Ahora bien, el PND en su proyecto de Ley N. ${ }^{\circ} 227$ de 2019 y en el documento Bases del Plan Nacional de Desarrollo: Pacto por Colombia, pacto por la equidad, expone la realización de una hoja de ruta única para articular los instrumentos del acuerdo de paz como el PATR, los planes y programas sectoriales y territorial, y los mecanismos de financiación y ejecución. Dicha hoja de ruta aún no es clara en la metodología de construcción y tampoco en el carácter participativo, lo que sin duda representa un problema mayor en el proceso de implementación.

5. En articulación con lo anterior, la hoja de ruta única será creada para implementar la política de estabilización, bajo la coordinación de la Alta Consejería para el Posconflicto, acompañada técnicamente por el DNP y la ART. Esta última, con la Consejería para la Estabilización y la Consolidación, son las responsables de elaborar, coordinar y articular la hoja de ruta única y los instrumentos de ejecución y financiación. El reto se centra en una articulación real de las instituciones, con participación comunitaria y financiación adecuada. Además, deberán coordinar con las organizaciones y comunidades la aplicabilidad territorial.

6. Ahora bien, de acuerdo con el PND se llevarán acciones efectivas para la política de estabilización, a partir de la creación de las Zonas Estratégicas de Intervención Integral (ZEII), esperando que en algunos municipios se articulen con los PDET. ¿Cómo se articularán las ZEII con el PDET? ¿Cómo serán los mecanismos para que los territorios no solamente sean considerados objetivo de estabilización con fuerza pública, sino que continúen potencializando el diálogo social?

7. Armonizar la visión sobre el desarrollo que plantea el actual Gobierno en específico con la política de estabilización y las que plantean las comunidades para la construcción de territorios para el bienestar y pervivencia de las comunidades. La visión de estabilización del Gobierno evoca un nuevo abordaje de la seguridad con sentido de legalidad, desde 
una perspectiva amplia que se materializa en el control militar, policial e institucional del territorio.

8. Claridad en el manejo de las fuentes de financiación orientada para la implementación del Acuerdo de paz, pues la falta de transparencia o de escenarios que permitan veeduría en el gasto, posibilitará la desconfianza en la labor realizada.

9. Implementación del Acuerdo de paz como un ejercicio de participación política, de democracia y de diálogo.

\section{Retos institucionales}

1. Especial atención se debe prestar a la estructura organizativa de la ART que en un principio se pensó para el diseño y la construcción metodológica del PDET, y tal como se ha encontrado en territorio no está preparada para el diseño y metodología que garantice de manera adecuada y participativa la implementación de las iniciativas. Además, para que las comunidades adelanten de manera efectiva el seguimiento y veeduría de las diferentes iniciativas de corte municipal y regional en el marco del PDET.

2. Unido con el anterior elemento, no ha sido posible conocer de manera clara los mecanismos de priorización que tiene la ART para la implementación de las iniciativas de corte regional que permitan la transformación de este nivel territorial, lo que deja por fuera la incidencia de las comunidades y organizaciones que participaron en el diseño de estas iniciativas. Teniendo en cuenta, además, que con la hoja de ruta única la ART definirá proyectos de impacto regional que serán gestionados a partir de los pactos territoriales, por cuanto recalca la pregunta sobre cómo garantizar la participación comunitaria en dichos impactos y la priorización de las iniciativas, espíritu primario del PDET.

3. Efectiva articulación que realiza la ART con las instituciones, ministerios y programas responsables de cumplir las iniciativas en el PATR, en primer momento, pues estos últimos años ha sido evidente la falta de 
articulación de las instituciones para que de manera integral y coordinada atiendan las solicitudes de las comunidades rurales.

4. Por otro lado, territorios como el del Cauca evidencia un problema estructural en la articulación de las instituciones responsables de la implementación normativa y programática del Acuerdo de Paz. Entre otras, es posible ubicar la falta de articulación entre programas como el PNIS y el PDET. Si continúa esta desarticulación a nivel territorial, e incluso con la escala nacional, será muy difícil que sea efectiva la implementación de los acuerdos.

\section{Retos participativos}

1. La reconfiguración de las dinámicas del conflicto armado en muchos de estos municipios, en relación con el alto número de líderes y lideresas sociales asesinados o amenazados, evidencia uno de los retos mayores que tiene la implementación del PDET en esta región, ya que no es posible garantizar la participación de las comunidades y sus iniciativas de paz en estas condiciones.

2. Puesta en marcha de escenarios que en términos municipales y departamentales garanticen la participación ciudadana en defensa de la paz, tales como los consejos de paz, comités de paz, mesas interculturales, mesas de diálogo y otros escenarios que serán claves para el ejercicio participativo e incidente en la política pública de paz. Incluso se deberá viabilizar el funcionamiento de escenarios para planeación ciudadana como los Consejos Municipales para el Desarrollo Rural (CMDR).

\section{Retos comunitarios}

1. En relación con lo anterior, otro de los puntos clave es la reconfiguración del conflicto armado en la región, donde es posible ubicar alertas tempranas de desplazamiento por presencia de grupos paramilitares o disidencias, la llegada de nuevos actores armados a la región e incluso se ha detectado incidencia y presencia de carteles internacionales. Es posible ubicar "cambios geoestratégicos por parte de actores armados ilegales, lo cual reconfiguró el conflicto armado en varios municipios de la región. 
Así, en zonas donde antes había una presencia dominante de las FARC-EP, ahora es posible reconocer la presencia del ELN (en el caso del norte el Cauca) y de estructuras narco-paramilitares como el cartel del Golfo) y el cartel de Sinaloa (Indepaz, 2018)" (Melo, Ante y Duque, 2019)

2. Es importante evidencia que entre el 1 de enero de 2016 y el 8 de septiembre de 2019, a nivel nacional cerca de 777 personas líderes sociales y defensoras de derechos humanos fueron asesinadas en Colombia (CACEP, Marcha Patriótica e Indepaz, 2019). En este balance, el departamento del Cauca ocupa el primer puesto con 169 casos y el Valle del Cauca el cuarto con 62. Para ambos casos el aumento es significativo para el año 2018.

3. Tal como lo han demostrado los voceros del Espacio Regional de Paz del Cauca (ERPAZ), es necesario fortalecer un movimiento de organizaciones y comunidades en defensa de la paz como derecho.

\section{Conclusiones}

El análisis de los retos debe ser integrado, lo que planteará una acción real en los territorios garantizando la participación e incidencia comunitaria.

El análisis esboza la responsabilidad no solamente Estatal por la implementación efectiva del Acuerdo de Paz, sino también la responsabilidad comunitaria en aras de potencializar escenarios para la veeduría, seguimiento e incidencia en la construcción de paz territorial, fortaleciendo los ejercicios de diálogo social intercultural.

En próximos análisis es preciso aventurarnos a debatir sobre los retos de la implementación de paz en relación al tema de sustitución de cultivos de uso ilícito, víctimas, garantía a la vida, iniciativas territoriales y otros aspectos que permitirán plantear dinámicas territoriales en la región Alto Patía y Norte del Cauca. 


\section{Referencias}

Agencia de Renovación del Territorio-Presidencia de la República. (11 de diciembre de 2018). Plan de acción para la transformación regional (PTR). Subregión Alto Patía y Norte del Cauca. Bogotá: Autor.

Ante, Rodrigo; Correa, María; Vergara, Edilberto y Duque, Katerine. (2019). Lectura Territorial región Alto Patía y Norte del Cauca. Fortalecimiento de las capacidades de las Organizaciones de la Sociedad Civil para la participación, la gobernanza y la innovación social. Apoyo a la participación incidente y al proceso de construcción de paz en el Norte del Cauca y Alto Patía. Documento sin publicar. Cali: Instituto de Estudios Interculturales Pontificia Universidad Javeriana/Unión Europea en Colombia.

CACEP, Marcha Patriótica e Indepaz (2019). Informe Especial Violaciones a los Derechos Humanos en tiempos de paz. Consultado en: http://www.indepaz.org.co/wp-content/uploads/2019/09/Informe-Violaciones-a-los-Derechos-Humanos-en-tiempos-de-Paz.-Septiembre-de-2019-18-09-19.pdf

Departamento Administrativo de la Presidencia de la República. Decreto 2278 de 2019. Por el cual se adiciona la Parte 6 del Libro 2 del Decreto 1081 de 2015 Único Reglamentario del Sector Presidencia de la República, se reglamenta parcialmente la Ley 1941 de 2018, en concordancia con los parágrafos $1^{\circ}$ y $2^{\circ}$ del artículo 281 de la Ley 1955 de 2019, en lo que hace referencia a la implementación de las Zonas Estratégicas de Intervención Integral zEII y se dictan otras disposiciones. Diciembre 16 de 2019. D.O No 51.192. Consultado en suin-juriscol: http://suin-juriscol.gov.co/viewDocument.asp?id $=30038716$

Duarte, Carlos; Duque, Katherine y Quintero, Alejandra. (2018). Siembra Campesina: material para el trabajo territorial y comunitario de las comunidades campesinas. Cali: Pontificia Universidad Javeriana.

Ermida, Oscar. (2006). Diálogo Social: Teoría y Práctica. IUSLabor, (1). Consultado en ilo.int: http://www.ilo.int/wcmsp5/groups/public/---ed_ dialogue/---actrav/documents/publication/wcms_117509.pdf\#page $=63$

Gobierno Nacional y Farc-EP. (2016). Acuerdo Final para la terminación del conflicto y la construcción de una paz estable y duradera. Consultado en altocomisionadoparalapaz: http://www.altocomisionadoparalapaz.gov.co/ 
procesos-y-conversaciones/Documentos \% 20compartidos/24-11-2016NuevoAcuerdoFinal.pdf

Gros, Héctor. (2005). El derecho Humano a la Paz. Anuario de Derecho Constitucional Latinoamericano. Consultado en corteidh: http://corteidh.or.cr/ tablas/R21744.pdf

Gutiérrez, Alderid. (2012). Negociaciones de paz en Colombia, 1982-2009. Un Estado de Arte. Estudios políticos, 40, ISSN 0121-5167. Medellín, enerojunio de 2012: pp. 175-200. Consultado en: http://www.scielo.org.co/pdf/ espo/n40/n40a09.pdf

Instituto Kroc. (2018). Segundo Informe sobre el Estado efectivo de implementación del acuerdo de paz en Colombia diciembre 2016-mayo 2018. Consultado en kroc.nd: https://kroc.nd.edu/assets/284864/informe_2_instituto_kroc_final_with_logos.pdf

Instituto Kroc. (2019). Actualización. Informe 3 del Instituto Kroc. Hacia una paz de calidad en Colombia. Consultado en kroc.nd: https://kroc.nd.edu/ assets/315919/190408_actualizacio_n_informe_3_instituto_kroc_feb19.pdf

Ishikawa, Junko. (2004). Aspectos clave del Diálogo Social Nacional: un documento de referencia sobre el diálogo social. Ginebra: Oficina Internacional del Trabajo. Consultado en guía.oitcinterfor: http://guia.oitcinterfor.org/ sites/default/files/conocimientos/aspectos_clave_del_DS_nacional.pdf

Jaramillo, Sergio. (2016). La Paz Territorial. Bogotá: Oficina del Alto Comisionado para la Paz. Consultado en interaktive: https://interaktive-demokratie.org/files/downloads/La-Paz-Territorial.pdf

Kahane, Adam (2004). Solving Tough Problems: An Open Way of Talking, Listening and Creating New Realities. San Francisco: Berrett-Koehlet.

Melo, Juanita; Ante, Rodrigo y Duque, Katerine. (2019). Reconfiguración del Conflicto Armado- Norte del Cauca y Buenaventura. [La Silla Llena]. Consultado en lasillavacia: https://lasillavacia.com/silla-llena/red-de-lapaz/reconfiguracion-del-conflicto-armado-norte-del-cauca-y-buenaventura-71908

Ministerio de Agricultura y Desarrollo Rural. Decreto 893 de 2017. Por el cual se crean los Programas de Desarrollo con Enfoque Territorial- PDET. Mayo 28 de 2017. D.O No 50.247. Consultado en es.presidencia: http:// 
es.presidencia.gov.co/normativa/normativa/DECRETO \% 20893 \% 20 DEL \% 2028\% 20DE\% 20MAYO \% 20DE\% 202017.pdf

Mínguez, Xavier. (2015). Métodos de Diálogo con Grandes Grupos. Herramientas para afrontar la complejidad. Revista de Estudios Sociales Número 51. Bogotá, enero-marzo 2015. Consultado en: http://www.scielo.org.co/pdf/ res/n51/n51a15.pdf

OIT (2017). Diálogo Social Tripartito de Ámbito Nacional. Un guía de la oIT para una mejor gobernanza. Oficina Internacional del Trabajo, Unidad de diálogo Social y Tripartismo, Departamento de Gobernanza y Tripartismo, Italia. Consultado en: https://www.ilo.org/wcmsp5/groups/public/---ed_ dialogue/---dialogue/documents/publication/wcms_548547.pdf

Panikkar, Raimon. (2006). Paz e interculturalidad. Una reflexión filosófica. Barcelona: Editorial Herder.

Presidencia de la República. (s.f.) ¿Qué es un PDET? Consultado en Colombia renace postconflicto: http://especiales.presidencia.gov.co/ Documents/20170718-PDET/que-son-PDET.html

Presidencia de la República. (2018). Plan de Acción para la Transformación Regional- PATR. Subregión Alto Patía y Norte del Cauca. Popayán: Renovación del Territorio. Presidencia de la República.

Pruitt, Bettye y Thomas, Philip. (2008). Diálogo Democrático - Un Manual para Practicantes. Estocolmo: Programa de las Naciones Unidas para el Desarrollo. Consultado en oas.org: https://www.oas.org/es/sap/dsdme/pubs/ DIAL_\%20DEMO_s.pdf

Rodríguez, Tania; Espitia, Luisa; Ante, Rodrigo; Muñoz, Manuel y Duarte, Carlos. (2017). Tejiendo territorios. Conflictos territoriales y comunidades indígenas en el Valle del Cauca. Cali: Pontificia Universidad Javeriana.

Roth André-Noël (2003). Políticas públicas. Formulación, implementación y evaluación. Ediciones Aurora. Bogotá, Colombia. Consultado en: https://campusvirtual.univalle.edu.co/moodle/pluginfile.php/1195979/ mod_resource/content/1/Pol \% C3 \% ADticas \% 20p \% C3 \% BAblicas. \% 20 formulaci \% C3 \% B3n \% 2C \% 20implementaci \% C3 \% B3n \% 20y \% 20 evaluaci \%C3\%B3n. \%20Roth \%20Deubel.pdf 
Santos, Miguel. (1993). La evaluación: un proceso de diálogo, comprensión y mejora. Investigación en la Escuela, (20), 23-35. Consultado en idus. us: $\quad$ https://idus.us.es/xmlui/bitstream/handle/11441/59547/La \%20 evaluaci \% c3\% b3n \% 20un \% 20proceso \% 20de\% 20di \% c3 \%a1logo \% 2c \% 20 comprensi \% c3\%b3n \% 20y \% 20mejora.pdf? sequence = 1\&isAllowed = y

Toro, Bernardo. (2018). Paz y democracia: principios básicos. Palabra Maestra (Blog). Consultado en El Espectador: https://blogs.elespectador.com/actualidad/palabra-maestra/paz-democracia-principios-basicos-bernardo-toro

Walsh, Catherine. (2005). Interculturalidad, conocimientos y decolonialidad. Signo y Pensamiento, 24(46), 39-50.

Wittingham, María. (2010).¿Qué es la gobernanza y para qué sirve? Revista Análisis Internacional RAI. Número 2. 